\title{
Solution to the Power Crisis in Ghana: Optimization of the Transmission and Distribution of the ECG Network
}

\author{
Patrick Fiati \\ Cape Coast Technical University \\ P.O.Box DL 50 \\ Cape Coast, Ghana
}

\begin{abstract}
Power is one of the most important factors for a developing country like Ghana. Like the rest of the countries of the world, the demand for power is increasing day by day in our country. At present, power failure has become an acute problem for this country. It has become hard to solve the power crisis. There are several reasons behind this problem such as limitation of resources, low generation capacity, high demand, derated capacity of power station machineries etc. To become a developed country, Ghana needs to overcome the problem of power crisis soon. Electricity is a very important factor in developing the economy and the standard of living of a country. It must be generated using the national resource of that country. Ghana largely depends on natural gas and hydro power stations to generate major portion of power. The country lags behind than its expected production capacity. Though many power generation units have been added to the national grid to solve the power crisis issue, it is not enough. High demand and increasing need of power have created challenge for the power stations to meet the demand. In our country, a major portion of total population still does not have the access to electricity. Only $10 \%$ of the rural households have electricity connection and there are some parts of Ghana which will not get the access of electricity connection from the national grid within next 30 years.
\end{abstract}

\section{Keywords}

Optimization, Generation, Transmission, Distribution, ECG

\section{INTRODUCTION}

At present, 53\% of the total electricity generation of Ghana is from the power plants under public sector and $47 \%$ of the net generation of the country is from private sector. Even though many extra units both from public and private sector have been added to the national grid, the power crisis is still a big issue in the country. So due to high demand, maximum generation of 2087 MW in 1995-1996, 2114 MW in 1996$1997,3218 \mathrm{MW}$ in 2001-2002, $3458 \mathrm{MW}$ in 2002-2003, 3622 MW in 2003-2004, 3751 MW in 2004- 05, 3812 in 2005- 06, 3718 in 2006-07, 4130 MW in 2007-08, $4037 \mathrm{MW}$ in 2008-09 could not end the power crisis in the country. In public sector, most of our power stations of the country have become very old and they are operating lower than their rated capacity with detoriated machineries. The demand of electricity cannot be met due to this insufficient production of electricity around the country and as most of our power stations depend primarily on natural gas as fuel, because of the shortage of gas supply some power plants are unable to produce power of their rated generation capacity. Beside natural gas based power plants, other power plants are Hydro Electric Plant at
Akosombo, the thermal plant at Aboadze, Takoradi and several other power plants around the country. But the insufficient gas supply has decreased the power generation capacity in the whole country. In most cases, we have failed to use our national resources to get maximum power output. Industrial production and household life are regularly hampered due to regular load shedding problem which is hampering our economy as well as making us lag behind. As a result of the power crisis, degradation of the fossil fuel resource, deforestation, environmental pollution is going on which is causing natural disasters. If this situation continues, industries will face losses due to power crisis; production will become low and eventually economy of the country will fall behind which will cause the major industries to shut down resulting into poverty and unemployment. We can get rid of this situation by the optimization of the Transmission and Distribution part of electricity network process.

\section{SUMMARY}

FIELD-FORCE AUTOMATION to automate infrastructure inspections for both field and office operations as well as the recording and submission of inspections and work planning. An effective mobile strategy links the corporate Back Office to the Field workforce [1]. Today electric utilities can achieve measurable business benefits for a range of mobile operations with end-to-end solutions. By improving the productivity of mobile workers, utilities can increase revenue, cut expenses and improve customer service. Fortis Alberta's centralized O\&M Team used this utility to save about US $\$ 333,000$ per year which allowed the company to increase their maintenance budget by $\$ 10,000,000$ without increasing their staff [2].

According to The World Bank (2014), about $24 \%$ of the population of Sub-Africa has access to electricity. Access to electricity has been described as the percentage of the population who are connected to national electricity grid. Significant feat has been achieved to the extent that the electricity penetration in Ghana has increased to about $76 \%$, only second to South Africa which has access rate of over $80 \%$. However, La Cote D'Ivoire has 70 per cent of electricity penetration, while only $24 \%$ of mainlands Tanzanians are connected to national electricity grid. However, Burkina Faso has merely $13 \%$ access rate. However, one of the main challenges in the power sector in Ghana remains erratic electricity supply and high indebtedness.

It is common knowledge that this state of affairs are caused by low tariffs, high cost of generation, non-payment of bills, poor revenue mobilisation, price under recoveries, illegal connections, mismanagements and extreme politicisation of 
power issues. Operational inefficiencies have also led to high transmission and distribution losses. Therefore, if we really want to overcome these obstacles, we must be prepared to do things differently. The repetition of the above variables could only produce the same results.

Low tariffs have been responsible for high level of indebtedness in the power sector in Ghana. The recent debt quagmire has the potential of crippling the power sector unless adequate measures are put in place to rectify it. The debts owe by the Volta River Authority leaves sour taste in the mouths of most Ghanaians. The VRA huge debts incurred from Ghana National Gas Company (GNGC) and Nigeria-Gas $(\mathrm{N}-\mathrm{Gas})$ to the tune of $\$ 150$ million and over $\$ 180$ million respectively are mainly due to maladministration.

What makes the situation even worst is the debt the VRA owes GNGC. This whopping amount within a short period of its commercial operations leaves much to be desired. The Chief Executive of GNGC has been making several distress appeals for the debt to be settled immediately went without a listening ear. The upstream (Generation), midstream (transmission) and downstream (distribution) companies are all highly indebted one way or the other. Therefore, the balance sheets of all the value chain companies in the power sector remain very weak.

The cost dynamics have also changed ever since thermal generation became a base load. The costs of light crude oil, heavy crude oil and lean gas are quite expensive and imported from markets elsewhere. The cost of fuel generation is estimated to be 30 pesewas for a kilowatt of electricity, but both residential and industrial consumers pay only 15 pesewas for one kilowatt of electricity as approved by the Public Utility and Regulatory Commission (PURC). This represents under recoveries of about 50 per cent of the generation cost incurred by the generation companies.

The increasing cost of production without corresponding tariff hikes makes companies lose substantial investments [3]. As it was reported the VRA invested $\$ 1.3$ billion to generate electricity but could only managed to collect a total revenue of $\$ 900$ million. This investment alone made under recovery of $\$ 400$ million. Consequently, the VRA has owed banks to a tune of $\$ 1.3$ billion, making it extremely difficult for it to settle its debts for gas supplies from both Ghana National Gas Company and Nigeria Gas(N-Gas).

Therefore, the N-Gas threats to cut gas supply over the accumulation of debts was predictable but the implication is dire for the electricity supply unless adequate mechanisms are put in place to defray the obligation. Fortunately, the Ministry of Power has rescheduled the payment plan with N-Gas, but lasting solution should be found to the debacle to forestall acute blackout across the country.

Subsequently, high indebtedness of the VRA is as a result of the ECG, VALCO and GRIDCo's refusal to honour their side of the bargain. Sadly, the power purchase agreement in the country does not favour VRA. The ECG has an obligation to initially pay IPPs and GRIDCo before it could consider payment to the VRA. More so, while electricity consumers pay ECG in the local currency, the power purchase agreement makes it mandatory for the ECG to pay the IPPs in dollar equivalent using current foreign exchange rates. Hence, the distribution company has an accumulated debt of GHc1.2 billion partly due to exchange volatility, price under recoveries and low tariffs.

Another big challenge that deprives the ECG of adequate funds is failure of both state and private companies to pay their electricity bills. Many state institutions especially, have developed a sense of entitlement towards utilisation of electricity. Ironically, the state institutions are reported to owe ECG over 500 million dollars. Therefore, the recent crusade that has been embarked upon to disconnect defaulting consumers needs to be supported by all. For instance, the ECG recently disconnected Koforidua Polytechnic, National Identification Authority (NIA), GBC transmission towers at Amedzofe and Cape Coast Teaching Hospital over unpaid bills. It is incumbent on the government to come out with a road map towards settling all debt owed the ECG as this may be a catalyst for further investments.

These remedies must be fast tracked to save the company from crumbling financially due to non-payment of bills. Mopping up the debts owe by these institutions can improve its financial position and subsequently the VRA. Also, about 425 consumers have been sued by ECG over non-payment of bills. However, this exercise is normally being frustrated by various governments as a result of lack of political will.The availability of electricity provides an avenue for economic and technological advancements. It is a very sensitive variable with political and economic implications on the effectiveness of industries in most countries. Therefore, fixing of tariffs becomes veritable grounds for losing or winning more votes during elections.

One more obstacle that makes the operations of the ECG worse off is the activities of illegal connections. The ECG in collaboration with police and military clamped down on more than 88 illegal power consumers in the Eastern Region alone. Recently, ECG also crackdown about 20 illegal and defaulting power consumers at Danyame and Suame both in Ashanti Region. These culprits included drinking bars, hair dressing salons, barbering shops, restaurants and printing press. This exercise is aimed at improving revenue collection and discouraging illegal connections in the country. To achieve a full impact of the exercise, the culprits should be made to face the full rigorous of the law.

Another critical aspects that need to be addressed in the value chain by GRIDCo and ECG are transmission and distribution losses. Transmission and distribution losses occur when electricity is lost between a point of supply and a point of consumption. According to the GRIDCo (2015), its transmission network loses is as high as $30 \%$ of power through transmission losses and illegal connections. This is very high considering that the global threshold of $3.5 \%$. The ECG's inability to minimise the distribution losses is a serious dent in its operations. It also records distribution system losses of $22 \%$ which is far above the international benchmark of $15 \%$.

The obstacles are unattractive to the generating companies in the value chain. It is clear that these inefficiencies in the electricity value chain, if not addressed, can deny the country the Millennium Challenge Compact (II) into the power sector. Drastic measures are therefore, needed to sanitise and rationalise the power sector and improve their financial and operational efficiencies if the country is to access the fund. EPRI believes that the above challenges have cost implications on the tariff regimes. Hence, overcoming them will go a long way to addressing the high cost of electricity. 
These challenges must be sorted out as practical as possible to reduce our debt profile and improve the efficiency of the national electricity grid. It is crystal clear to every Ghanaian by now that the electricity crisis has everything to do with both technical and financial problems. At a point, it was observed to be technical one due to the breakdown and maintenance of certain plants as well as poor reservoir management associated with hydropower, but now the financial challenge has strongly emerged.

The sad story is that the consumers have always expressed hostilities whenever proposal for payment of realistic tariffs is suggested and successive governments also lack political will to tackle the problem head on. It is unfortunate that Ghanaians always mix partisanship with economic reality in their public discourse. However, the transition from hydropower to thermal power signals the shift to high cost of generation and subsequently high tariffs to consumers. Sanitizing and improving the financial performance of all the companies will eventually enhance reliable, sustainable electricity supply in the country. The financial wellbeing of the off-taker (ECG) will eventually translate upwards to the GRIDCo and VRA.

Adequate measures should therefore be adopted to systematically address these bottlenecks to give relief to the power sector companies. Lately, public fora were held throughout the country by PURC to solicit support for intended increments of utility tariffs to about $100 \%$. Even though public outcry is still loud against the proposed increases, we must be ready to accept the fact that the era of cheap electricity is long gone with the introduction of more thermal in the generation mix. Much as the consumers want value of their bills, so do the companies want returns on their investments. Therefore, the issue of the payment of realistic tariffs must be discussed dispassionately and in the national interest.

\section{CONCLUSION}

As a result of the power crisis, degradation of the fossil fuel resource, deforestation, environmental pollution is going on which is causing natural disasters. If this situation continues, industries will face losses due to power crisis; production will become low and eventually economy of the country will fall behind which will cause the major industries to shut down resulting into poverty and unemployment. We can get rid of this situation by the Optimization of the Transmission and Distribution part of electricity network process of Electricity Company of Ghana (ECG).

\section{REFERENCES}

[1] www.mypplelectric.com, Transmission Line Monitoring System(T\&DWorld,TransmissionDistributionWorld@en ews.tdworld.com)

[2] www.nexans.com, Email:marcom.info@ nexans.com

[3] www.epri.com, Electric Power Research Institute (EPRI: Palo Alto, California, USA) 